\title{
Standardizing anesthesia medication drawers using human factors and quality assurance methods
}

\section{La standardisation des tiroirs du chariot d'anesthésie sur la base de facteurs humains et de méthodes de contrôle de la qualité}

\author{
Jonas Shultz, MSc $\cdot$ Jan M. Davies, FRCPC $\cdot$ Jeff Caird, PhD \\ Susan Chisholm, MSc $\cdot$ Karen Ruggles, BA $\cdot$ Raymond Puls, RRT
}

Received: 20 October 2009/Accepted: 12 January 2010/Published online: 9 February 2010

(C) Canadian Anesthesiologists' Society 2010

\begin{abstract}
Purpose In Calgary, each of the three acute-care adult hospitals had different anesthetic medication carts with their own type and layout of anesthetic medications. A number of anesthesiologists moved among the different sites, increasing the potential for medication errors. The objective of this study was to identify the anesthetic medications to include and to determine how they should be grouped and positioned in a standardized anesthesia medication cart drawer.

Methods A standardized list of medications was established. Next, the anesthesia medication cart drawer was filled and photographed, and a jigsaw puzzle was made
\end{abstract}

J. Shultz, MSc $\cdot$ S. Chisholm, MSc

Patient Safety Division, Alberta Health Services, Calgary, AB, Canada

J. M. Davies, FRCPC

Department of Anesthesia, University of Calgary, Calgary, AB, Canada

J. Caird, $\mathrm{PhD}$

Department of Psychology, University of Calgary, Calgary, AB, Canada

\section{K. Ruggles, BA}

Clinical Quality Support, Alberta Health Services, Calgary, AB, Canada

R. Puls, RRT

Department of Anesthesia, Alberta Health Services, Calgary, $\mathrm{AB}$, Canada

J. Shultz, MSc ( $\square)$

Human Factors Consultant, Patient Safety Division,

Alberta Health Services, Second floor, Northwest II,

4520 - 16th Avenue NW, Calgary, AB T3B 0M6, Canada

e-mail: jonas.shultz@albertahealthservices.ca from the photograph. Anesthesiologists and anesthesia assistants arranged the jigsaw pieces into an ideal drawer. Participants verbalized their rationale for the position of each puzzle piece. Results were collated and analyzed. A mock drawer was developed and reviewed by department members, and minor modifications were made.

Results A final standardized medication drawer (content and positioning) was developed over 30 months, with agreement from anesthesiologists $(n=12)$ and anesthesia assistants $(n=3)$ at the three hospitals. Guidelines for placing each medication in the drawer included grouping them according to order of use, frequency of use, similarity of action, severity of harm from misuse, and lack of similar appearance. A finalized template was used for a standardized drawer and installed in every operating room of the three hospitals.

Conclusion Implementation of the standardized medication drawer is expected to reduce the likelihood of medication errors. Future research should include testing the clinical implications of this standardization and applying the methodology to other areas.

\section{Résumé}

Objectif À Calgary, les trois hôpitaux pour soins aigus aux adultes disposaient chacun de chariots d'anesthésie différents. Chaque chariot arborait différents types et différentes dispositions de médicaments anesthésiques. Plusieurs anesthésiologistes ont migré d'un site à un autre, augmentant le risque de commettre des erreurs de médication. L'objectif de cette étude était d'identifier les médicaments anesthésiques à inclure et de déterminer leur regroupement et leur disposition dans un tiroir de chariot d'anesthésie standardisé.

Méthode Une liste standarde de médicaments a été établie. Le tiroir du chariot d'anesthésie a ensuite été 
rempli et photographié, et un casse-tête a été créé à partir de la photographie. On a demandé aux anesthésiologistes et aux assistants en anesthésie de disposer les pièces $d u$ casse-tête afin qu'il reflète leur tiroir d'anesthésie idéal. Les participants ont ensuite exprimé le raisonnement les ayant incités à positionner chaque pièce de casse-tête. Les résultats ont ét é colligés et analysés. Un tiroir factice a été élaboré et passé en revue par les membres des départements, et des modifications mineures ont été apportées. Résultats Un tiroir de médicaments standardisé final (contenu et disposition) a été élaboré sur une période de 30 mois, avec le consentement des anesthésiologistes $(n=12)$ et des assistants en anesthésie $(n=3)$ dans les trois hôpitaux. Parmi les directives pour le positionnement de chaque médicament dans le tiroir figurait leur regroupement selon l'ordre d'utilisation, la fréquence d'utilisation, la similitude d'action, la gravité des effets secondaires si mal utilisé et l'absence de ressemblance. Un modèle finaliséa été utilisé pour l'elaboration d'un tiroir standardisé et installé dans chaque salle d'opération dans les trois hôpitaux.

Conclusion Il est attendu que la mise en ouvre du tiroir de médicaments standardisé réduise la probabilité des erreurs d'administration médicamenteuse. Les recherches futures devraient s'employer à tester les implications cliniques d'une telle standardisation et à appliquer cette méthodologie à d'autres domaines.

A survey of Canadian anesthesiologists showed that $85 \%$ of participants had made at least one medication-related error or close call. ${ }^{1}$ Most frequently, these errors involved administering muscle relaxants rather than reversal agents, typically as a result of misidentified ampoules and vials or 'syringe swaps'. Also, survey respondents identified incorrectly stocked medications as one of the contributing factors. Almost two decades earlier, Currie et al. found a similar pattern of results in voluntarily submitted incident reports, and they suggested that erroneously injected medications were frequently administered from a correctly coded or labelled syringe ( $63 \%$ of the time).$^{2}$ Moreover, these authors noted that one-fifth of ampoule selection errors occurred because the cue to select the 'correct' ampoule was its location. Once selected, the likelihood of detecting the 'incorrect' medication before it was administered was relatively low (42\%).

Not standardizing the location of medications can contribute to the increased likelihood of an anesthesiologist selecting the incorrect medication or another individual stocking the incorrect medication. Also, inconsistently placing medications contributes to inefficiency, for instance, anesthesiologists and other healthcare providers must spend time looking for the medications in the various locations where they expect they will be found.
A number of potential solutions have been suggested. Currie et al. recommended the use of a physical template to standardize the storage of medication. ${ }^{2}$ Orser et al. recommended that future research examine potential interventions to reduce reliance on memory, including standardization. ${ }^{1}$ Other publications have suggested the need for the standardization of anesthetic medications and organizing the medication within anesthesia carts to reduce selection errors. $^{3-7}$

Standardization forces consistency of use, one of the most basic principles of usability engineering. ${ }^{8}$ The concept is relatively simple - items of information or objects should be consistently located in the same place to facilitate search, familiarity, and recognition. The concept of standardization has been applied to the use of insulin sliding scale protocols, resulting in reduced complexity of care and decreased frequency of hypoglycemic events. ${ }^{9}$ Standardization is also applicable to intensive care unit medication protocols. ${ }^{10}$ In this paper, however, the concept of standardization when applied to the practice of anesthesiology is narrowed to mean that all anesthesia carts (in all anesthetizing locations and sites where anesthesiologists or individuals who stock the same carts might work) should have the same content in the same layout. Standardization is particularly important for those who work with multiple carts between different hospitals in one city and those who work with multiple carts within one hospital.

Two publications from New Zealand include more detailed guidance about the standardization of anesthetic medication carts. In a review of evidence-based strategies to reduce medication-related errors, one of the five specific strong recommendations was that "formal organization of medication drawers and workspace should be used with attention to tidiness; position of ampoules and syringes; separation of similar or dangerous drugs; removal of dangerous drugs from the operating theatres". ${ }^{11}$ The authors' description of a new medication administration system integrated with an automated anesthesia record system included the layout of the medication drawers. Two drawers were used to "reduce congestion and provide for separation of commonly used drugs" (in the first or top drawer) from those that are potentially more dangerous or are needed only occasionally (in the second drawer). The latter included more 'hazardous' medications, such as inotropes, vasodilators, and electrolytes. Left to right ordering of medications reflected the sequence of administration, and front to back ordering represented the frequency of use. ${ }^{12}$

These recommendations can be summarized as follows: placing frequently used medications at the front of the drawer, separating medications with potential for severity of harm from misuse, and ordering from left to right according to sequence of use. While we did not disagree with these principles, we wished to confirm them and to 
determine if there were further guidelines for the layout of anesthesia medication drawers. In addition, we did not find guidance as to the methods that could be used to determine the optimal standardized layout. Therefore, we decided to study and develop principles to guide the contents and layout of a standardized anesthesia medication drawer.

\section{Method}

We undertook this five-part quality assurance project after successfully completing the Investigation Ethics Screen (for Quality Improvement, Quality Assurance, and Program Evaluation) for the Calgary Health Region. After we began this project, the Calgary Health Region underwent both internal and external reorganization and was incorporated into one large provincial region, Alberta Health Services. Consequently, we reviewed and successfully completed our project against the Alberta Research Ethics Community Consensus Initiative (ARECCI) screening tool. ${ }^{13}$

At the time of our investigation, adult anesthetic services were provided in the regional (urban) Department of Anesthesia by about 100 anesthesiologists performing approximately 60,000 anesthetics yearly for almost all types of surgical procedures (except cardiac, liver, and lung transplants). These procedures were performed in 51 operating rooms in three acute-care adult hospitals in Calgary - pediatric services are not included in this description. Hospital \#1 was the designated Level 1 Trauma Centre with services including cardiac surgery, neurosurgery, thoracic surgery, complex spine surgery, transplant surgery, major oncological surgery, and major plastic reconstructive surgery. Surgical services of Hospitals \#2 and \#3 included general surgery, gynecology, plastic surgery, and orthopedics. Hospital \#2 was the primary site for major vascular surgery. Hospital \#3 was the primary site for urology and ophthalmology.

This study was based on a set of Human Factors principles describing four categories of human limitations perception, mental model, attention, and memory - from which design guidelines have been developed. ${ }^{14}$ These guidelines are based on extensive empirical research that has been summarized into a useful format so that experimental studies do not have to be repeated for every aspect of a design. Perception principles / guidelines target the manner in which humans visually detect and process information based on experiences and expectations (e.g., reading from left to right). Mental model principles / guidelines assist humans in understanding how something works or functions (e.g., respiration). Attention principles / guidelines address when, where, and the length of time a display should divert the attention of a user (e.g., a lengthy search for a particular drug). Memory principles / guidelines recognize that humans cannot remember lists of items for a period of time or recall how to perform a particular task (e.g., remember a seldom-used generic drug name). We paid particular attention to the concepts of consistency and standardization of displays, which reduce the need to remember the location of items and facilitate access to information through experience.

The study itself consisted of four parts: a photographic survey, a medication questionnaire, the jigsaw method, and mock drawer feedback. Each of these is now described.

\section{Photographic survey}

To obtain a visual baseline of the layout of the anesthesia carts, we photographed their contents from the three adult hospitals. The photographs of the three anesthesia carts were analyzed using the Human Factors principles described above. Notations were made of each departure from the guidelines, with suggestions where improvements could be made to the anesthesia medication drawers.

\section{Medication questionnaire}

Creation of a standardized medication drawer also meant that we standardize the drawer contents. To do this, we first collated lists of the medications and their concentrations used at each of the three sites. The task of developing this standardized list was undertaken by the Regional Department of Anesthesia Quality Council, and it took 20 months to complete. We then developed a questionnaire that was sent electronically via the Site Chiefs at each hospital to every consultant anesthesiologist member of the Regional Department of Anesthesia. The questionnaire listed the medications and their concentrations contained in the sitespecific anesthesia carts and asked the respondents to indicate those medications that should be added or removed. We collated the returned questionnaires and then compared the results with the Regional Department's annual medication usage data to determine if each medication was used in sufficient quantities to warrant its inclusion in the drawer. The questionnaire was administered twice, and with both iterations, medications were removed from the list and/or a decision was made as to the concentration of medication that should be included. The Site Chiefs reviewed the compiled data and agreed to a region-wide standardized list of medications and their respective standardized concentrations to include in the top medication drawer of the anesthetic cart at all adult anesthetizing sites.

Jigsaw method

Participants who volunteered for this part of the study were recruited by members of the Regional Department of 
Anesthesia Quality Council. These participants were not necessarily the same individuals as those who responded to the medication questionnaire.

To determine the grouping and positioning of medications, participants individually performed a jigsaw puzzlelike task that elicited his/her preferred configuration of the anesthesia medication drawer. The standardized medication list was used to stock an anesthesia medication drawer with a few vials or ampoules of each standardized medication. The drawer was then photographed and each medication's generic name was added electronically. The photograph was printed in colour on a letter-sized $(8.5 \times 11$ inches $)$ piece of paper and was then cut up so that each piece depicted the individual drawer space for a specific medication.

Each participant was given the cut-up photograph with the 'jigsaw' pieces randomly arranged. The participant was first asked to complete a grouping task by sorting the medications into logical groupings. The experimenter noted how the medications were grouped and asked the participant to provide a category name for each group, e.g., induction agent. The frequency with which each medication was placed in a group with every other medication was then analyzed.

For the subsequent positioning task, each participant was asked to organize the medications into an ideal arrangement on a blank piece of paper as if it were a medication drawer. As the participants were completing the positioning task, they were asked to speak aloud and state the reason they were choosing particular arrangements of medications as well as indicate the locations of medications they considered important. This technique is known as the 'think aloud' protocol. $^{15}$ Transcriptions were made of the verbalized statements. General organizational principles were extracted and comparisons were made of the solutions for drawer arrangements developed by each of the individuals and the group. Specifically, each statement was coded into common themes (e.g., look-alikes or patterns of drug use) and grouped with similar responses from other participants.

Once the participant achieved a final positioning of the medications, the experimenter photographed this result. These photographs were used to code medication placement according to its position in the drawer relative to the front, back, right, or left. The collections of statements were discussed at length and compared with the coding of medication placement and the jigsaw pictures to determine the underlying organizational principles that could be used to guide the development of the mock medication drawer used for further feedback.

\section{Mock drawer feedback}

We developed and filled a drawer using the principles developed through the jigsaw method, and we solicited feedback about the general appearance of the drawer and the grouping and labelling of the medications. One of the authors (JS) took the mock drawer to each of the three adult sites. At Hospitals \#1 and \#3, visits were made to the Anesthesiologists' Lounge on two separate occasions. At Hospital \#2, a presentation was made at Departmental Rounds. Comments were transcribed, and the research team reviewed all the comments in order to incorporate the feedback. Minor modifications were also suggested by two senior anesthesiologists with aviation and Human Factors' expertise. As a result, further changes were made to the appearance, positioning, and labelling of the medication drawer.

\section{Results}

\section{Photographic survey}

Review of the photographs of the three adult anesthesia medication carts revealed lack of consistent drawer organization and labelling. As shown in Figure 1, some medications, such as propofol, epinephrine, and naloxone were positioned in different locations in each of the three hospitals.

Some medications were stored in unlabelled containers (Figure 2a), and where labels were added, their visibility was often obstructed by the medication itself (Figure 2b). Other ampoules were stored upright in containers that blocked visibility of the ampoule and its label (Figure 2c), except for the coloured ring at the top of the ampoule. Inconsistencies in the horizontal or vertical orientation of vials and/or ampoules (Figure 2d) meant that users had to lift and rotate a vial or ampoule in order to properly identify it. Where present, labelling was printed in uppercase, thus reducing readability, and no information was given as to the medication's concentration.

\section{Medication questionnaire}

The list of medications and their usage stocked in the medication drawers (number of vials and ampoules sent from the pharmacy each year) differed widely among the three adult hospitals (Table 1).

The questionnaire soliciting feedback about the preliminary standardized list of medications was returned by $15 \%(n=15)$ of Regional Department of Anesthesia members. The results and usage data were reviewed by the Regional Department of Anesthesia Quality Council to determine the final standardized list of medications, their concentrations, and ampoule / vial size (Table 2).

Some medications were removed from the medication drawer and repositioned in another drawer of the anesthesia cart, e.g., salbutamol inhaler. Other medications were 

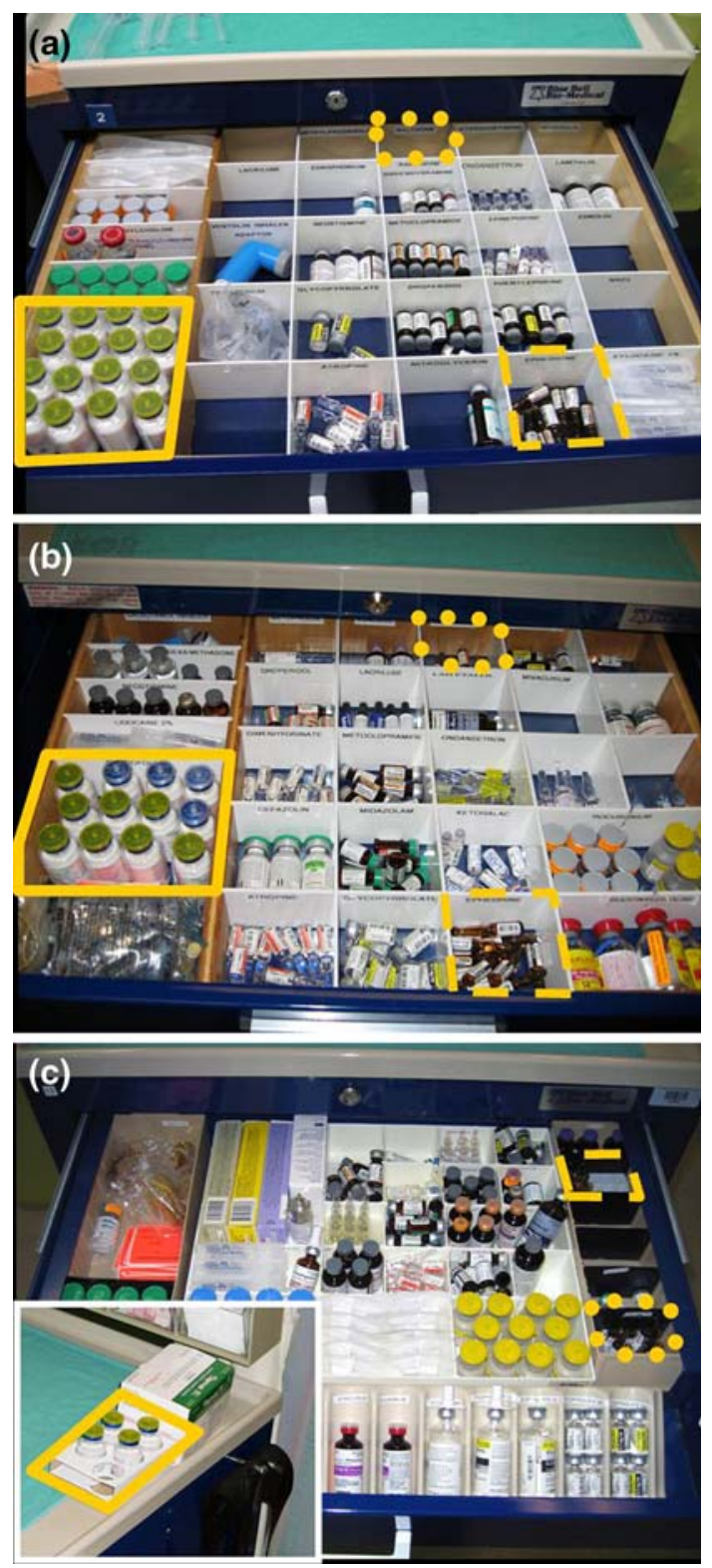

Fig. 1 Photographs of the three adult anesthesia medication carts showing a lack of consistent drawer organization and labelling. Some medications, such as propofol, epinephrine, and naloxone were positioned in different locations in each of the three hospitals: (a) Hospital \#1 (b) Hospital \#2 (c) Hospital \#3

removed from the anesthesia cart completely, although they were still available in the operating room for use, e.g., spinal bupivacaine. Table 1 also specifies the medications that were removed from the medication drawers at each of the three hospitals.

Jigsaw analysis

Data were collected from 12 anesthesiologists and three anesthesia assistants. These latter individuals with certification in Respiratory Therapy are specially selected and

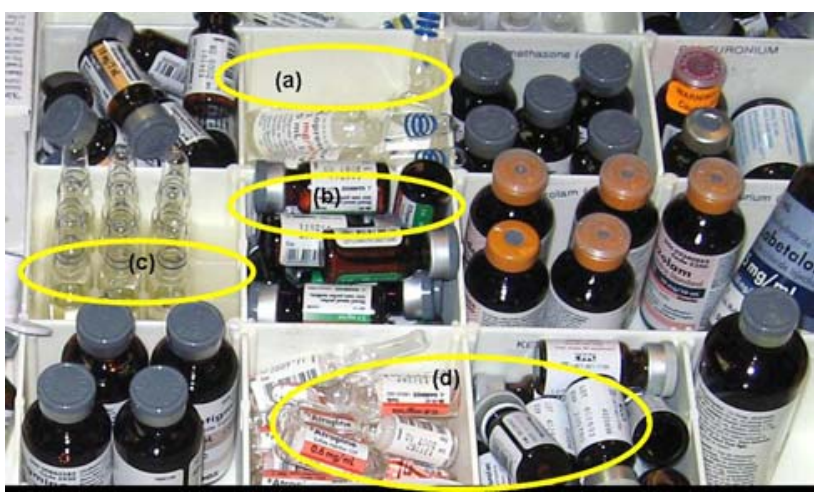

Fig. 2 Photograph showing variation in drawer organization and labelling: (a) Medication in unlabelled compartment (b) Medication obscuring the compartment label (c) Ampoule stored in an upright position, blocking the compartment label (d) Inconsistent vial / ampoule orientation

trained to participate as active members of the Anesthesia Care Team. There was an equal distribution of respondents among the three adult acute-care hospitals.

\section{Grouping task}

Since one participant did not complete the grouping task, the reported results are from 14 participants. As expected, most participants used clinical actions to group medications. For example, $92 \%$ of participants $(n=13)$ grouped the muscle relaxants (rocuronium and succinylcholine), $71 \%(n=10)$ grouped beta blockers (esmolol, labetalol, and metoprolol), and $79 \%(n=11)$ grouped the antiemetics (droperidol, metoclopramide, and ondansetron). Some medications were often not placed in groupings; these included cefazolin $71 \%(n=10)$, ketorolac $71 \%$ $(n=10)$, and lidocaine $71 \%(n=10)$.

\section{Positioning task}

The experimenter did not photograph the ideal arrangement for two participants. Consequently, data reported are for 13 participants. Many participants consistently positioned some medications, such as cefazolin, on the left (60\%), propofol at the front left $(66 \%)$, and muscle relaxants along the front $(50 \%)$. Figure 3 shows a typical jigsaw arrangement.

\section{Content analysis}

Common positioning patterns emerged from the subjects' 'think aloud' verbalizations. Participants tended to position medications in specific clusters, that is, based on how the medications were used. Participants also referred to classes of medications or overarching organizational schemata. Specific organizational schemes and participants' statements included: 
Table 1 Lists of different medications stocked initially in the medication drawers at each of the three adult acute care hospitals and the number of vial / ampoules used annually (usage)

\begin{tabular}{|c|c|c|c|c|c|}
\hline Hospital \#1 & Usage & Hospital \#2 & Usage & Hospital \#3 & Usage \\
\hline atropine & 3,492 & atropine & 2,845 & atracurium* & 364 \\
\hline cefazolin & 3,360 & bupivacaine $0.5 \% *$ & 1,407 & atropine & 2,671 \\
\hline diphenhydramine & 90 & bupivacaine $0.75 \% *$ & 1,455 & calcium chloride* & 4 \\
\hline droperidol & 630 & cefazolin & 2,054 & cefazolin & 2,913 \\
\hline edrophonium* & 84 & dexamethasone & 1,468 & dexamethasone & 2,354 \\
\hline ephedrine & 5,030 & dimenhydrinate* & 139 & droperidol & 754 \\
\hline epinephrine & 1,855 & droperidol & 1,270 & ephedrine & 2,650 \\
\hline glycopyrrolate & 10,290 & edrophonium* & 54 & epinephrine & 463 \\
\hline hydrocortisone* & 116 & ephedrine & 4,087 & ergonovine* & 0 \\
\hline labetalol & 232 & epinephrine & 845 & esmolol & 68 \\
\hline Lacri-lube* & 428 & esmolol & 160 & glycopyrrolate & 4,900 \\
\hline lidocaine $1 \%$ & 16,533 & glycopyrrolate & 8,884 & hydralazine* & 70 \\
\hline methylprednisolone* & 54 & ketorolac & 4,516 & ketorolac & 3,699 \\
\hline metoclopramide & 1,950 & labetalol & 225 & labetalol & 306 \\
\hline metoprolol & 1,044 & Lacri-lube* & 245 & lidocaine $2 \%$ & 5,375 \\
\hline naloxone & 166 & lidocaine $2 \%$ & 15,687 & metoclopramide & 3,561 \\
\hline neostigmine & 1,834 & metoclopramide & 1,412 & metoprolol & 361 \\
\hline nitroglycerin & 145 & metoprolol & 382 & midazolam & 3,430 \\
\hline phenylephrine & 7,708 & midazolam & 2,450 & mivacurium* & 0 \\
\hline propofol & 16,621 & mivacurium* & 0 & naloxone & 300 \\
\hline ranitidine* & 110 & naloxone & 112 & neostigmine & 1,858 \\
\hline rocuronium & 14,535 & neostigmine & 2,348 & ondansetron & 5,613 \\
\hline salbutamol adapter* & & ondansetron & 5,767 & oxytocin* & 456 \\
\hline salbutamol inhaler* & 130 & phenylephrine & 1,850 & pancuronium* & 57 \\
\hline sodium chloride* & 9 & propofol & 15,940 & phenylephrine & 1,357 \\
\hline succinylcholine & 2,893 & rocuronium & 6,810 & rocuronium & 5,746 \\
\hline thiopental* & 69 & salbutamol inhaler* & 67 & salbutamol adapter* & \\
\hline \multirow[t]{5}{*}{ vial adapters* } & & sodium chloride* & 0 & salbutamol inhaler* & 102 \\
\hline & & succinylcholine & 4,596 & sodium chloride & 10 \\
\hline & & & & sterile water & \\
\hline & & & & succinylcholine & 2,084 \\
\hline & & & & vial adapters & \\
\hline
\end{tabular}

* Indicates medication was not included in the standardized medication drawer

- Arrange medications by order and frequency of use

- "Use the left side for meds used at the start of the case."

- "Cefazolin is used at the beginning of the case and should be up front."

- "Rocuronium and succinylcholine should be stored in the front because they are used frequently."

\section{- Group medications by function}

- "Antiemetics should be stored together and arranged by frequency of use."

- Visually differentiate dangerous medications and store them in the back corners
- "Dangerous resuscitative drugs should be stored in the back."

- "Beta blockers, which are life threatening, should be stored in the back so they are easy to find but out of reach."

\section{- Separate look-alike medications}

- "Glycopyrrolate and phenylephrine need to be separated due to the bright yellow colour" (of the paper label).

Specific look-alike medications were frequently noted by a number of participants, all of whom suggested that they should not be stored next to each other. Examples of 
Table 2 The final standardized list of medications and their concentrations for the three adult acute care hospitals

\begin{tabular}{lll}
\hline Medication & \multicolumn{2}{l}{ Concentration and ampoule/vial size } \\
\hline atropine & $0.6 \mathrm{mg} / \mathrm{mL}^{-1}$ & $1 \mathrm{~mL}$ \\
cefazolin & $1 \mathrm{gm}$ & \\
dexamethasone & $4 \mathrm{mg} / \mathrm{mL}^{-1}$ & $5 \mathrm{~mL}$ \\
diphenhydrAMINE & $50 \mathrm{mg} / \mathrm{mL}^{-1}$ & $1 \mathrm{~mL}$ \\
droperidol & $2.5 \mathrm{mg} / \mathrm{mL}^{-1}$ & $2 \mathrm{~mL}$ \\
epHEDedrine & $50 \mathrm{mg} / \mathrm{mL}^{-1}$ & $1 \mathrm{~mL}$ \\
epINephrine & $1: 1000$ & $1 \mathrm{~mL}$ \\
esmolol & $10 \mathrm{mg} / \mathrm{mL}^{-1}$ & $10 \mathrm{~mL}$ \\
glycopyrrolate & $0.2 \mathrm{mg} / \mathrm{mL}^{-1}$ & $1 \mathrm{~mL}$ \\
ketorolac & $30 \mathrm{mg} / \mathrm{mL}^{-1}$ & $1 \mathrm{~mL}$ \\
labetalol & $5 \mathrm{mg} / \mathrm{mL}^{-1}$ & $20 \mathrm{~mL}$ \\
lidocaine $1 \% *$ & $10 \mathrm{mg} / \mathrm{mL}^{-1}$ & $5 \mathrm{~mL}$ \\
metoclopramide & $5 \mathrm{mg} / \mathrm{mL}^{-1}$ & $2 \mathrm{~mL}$ \\
metoprolol & $1 \mathrm{mg} / \mathrm{mL}^{-1}$ & $5 \mathrm{~mL}$ \\
midazolam & $1 \mathrm{mg} / \mathrm{mL}^{-1}$ & $2 \mathrm{~mL}$ \\
naloxone & $0.4 \mathrm{mg} / \mathrm{mL}^{-1}$ & $1 \mathrm{~mL}$ \\
neostigmine & $1 \mathrm{mg} / \mathrm{mL}^{-1}$ & $10 \mathrm{~mL}$ \\
nitroglycerine & $5 \mathrm{mg} / \mathrm{mL}^{-1}$ & $10 \mathrm{~mL}$ \\
ondansetron & $2 \mathrm{mg} / \mathrm{mL}^{-1}$ & $2 \mathrm{~mL}$ \\
phenyLEPHrine & $10 \mathrm{mg} / \mathrm{mL}^{-1}$ & $1 \mathrm{~mL}$ \\
propofol & $10 \mathrm{mg} / \mathrm{mL}^{-1}$ & $20 \mathrm{~mL}$ \\
rocuronium & $10 \mathrm{mg} / \mathrm{mL}^{-1}$ & $5 \mathrm{~mL}$ \\
succinylcholine & $20 \mathrm{mg} / \mathrm{mL}^{-1}$ & $20 \mathrm{~mL}$ \\
\hline & & \\
encechanged & &
\end{tabular}

* Since changed to lidocaine $2 \%$

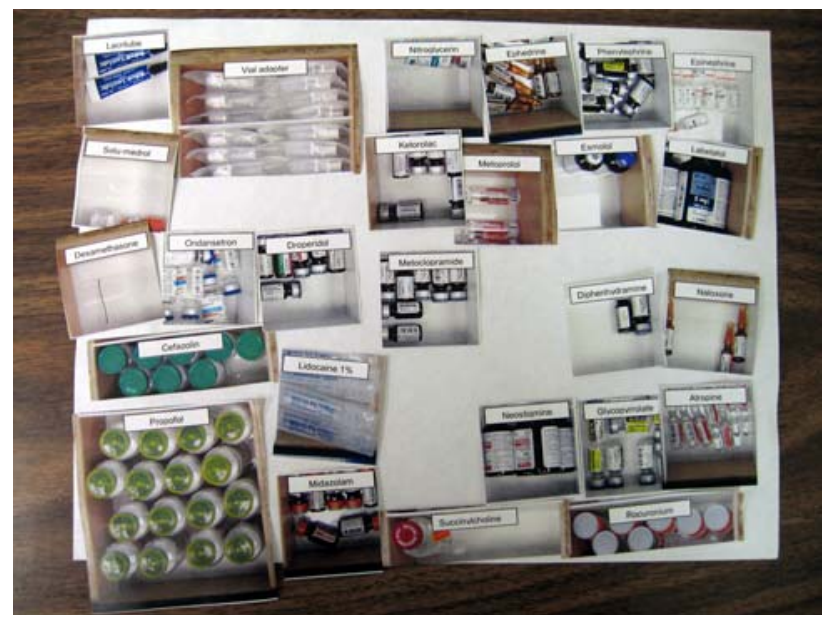

Fig. 3 Photograph of a completed positioning task by one participant (jigsaw arrangement)

these medications included atropine and epinephrine (noted by eight participants) as well as glycopyrrolate and phenylephrine (noted by six participants) (Figure 4).
Mock drawer feedback

The content of the mock drawer was based on the results of the previous stages of analysis, with medications positioned in the drawer according to four basic concepts:

(1) group medications by function;

(2) position groups of medications according to front-toback decreasing frequency of use and left-to-right chronological order of use;

(3) isolate those medications that anesthesiologists termed "dangerous"; and

(4) separate those medications that could potentially be confused with others similar in appearance.

The appearance of the mock drawer was changed to enhance medication and label contrast and visibility. First, a white drawer underlay replaced the blue liner found in many of the non-standardized drawers. Second, ampoules and vials were all positioned horizontally so as not to obscure the compartment label, except in the case of cefazolin, which was clearly distinguishable by the bright green flip top, the size of the vial, and the (white powder) medication.

Third, labels for each medication in each compartment were obtained from the Regional Pharmacy and followed previously developed guidelines for medication labelling. These guidelines included use of the medication's generic name, a san-serif font (Arial), sentence case, adequately sized font (size 16), and selective use of TALLman lettering. ${ }^{16}$ These medication labels were also added to the bottom of each compartment for better visibility from a standing position. In addition, a separate small round coloured and numbered label was added to the top right of the back of each medication compartment. The number on the round label gave the maximum stocking quantity of each medication. The placement of the number was designed to assist with rapid checking to ensure availability of sufficient quantities of medication without obstructing visibility of the actual medication label.

Fourth, a decision was made not to fill every compartment but to include empty compartments. This decision was based on facilitating further separation of the 'hazardous' medications from the 'routinely administered' medications and also on allowing flexibility for including additional medications in the future if needed. A red " $X$ " and an "Empty" label were placed on the back wall and base of each compartment that was intended to be kept empty. Fifth, red tape was applied along the top edges of the medication compartments within the drawer that were destined to hold the more 'hazardous' medications, such as vasopressors.

Verbal feedback about this mock drawer collected from 24 separate individuals across the three hospital sites 
Fig. 4 Photographs of lookalike pairs (a) ampoules of epinephrine and atropine, and (b) vials of phenylephrine and glycopyrrolate
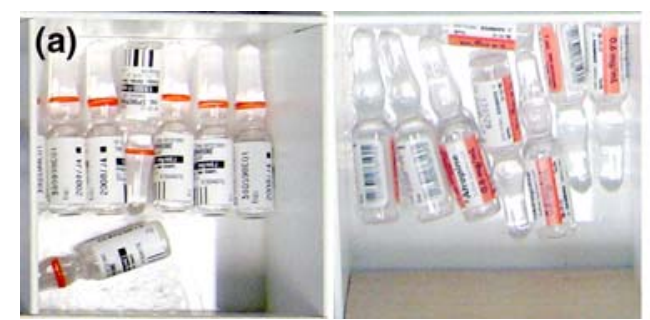

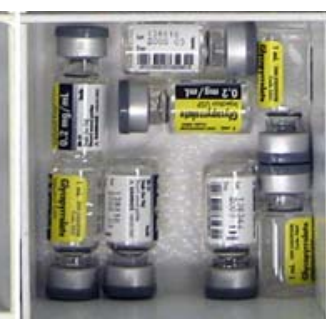

resulted in minor modifications. The adjustments included re-arranging the antiemetics horizontally (left to right) rather than vertically (front to back) in the drawer to be consistent with the positioning of other medication groupings. Red-coloured tape had been chosen initially to differentiate the potentially more hazardous medications. This tape was changed to black and white checkered tape because red is the Canadian Standards Association recommended colour used to indicate muscle relaxants on user-applied medication labels. ${ }^{\mathrm{A}}$

\section{Discussion}

Although anesthesiologists have been cited as leaders in efforts to improve patient safety, they are not immune to making medication-related errors. ${ }^{17} \mathrm{~A}$ number of recommendations have been brought forward to mitigate potential errors. Given that the location of a medication is one of the cues used to select ampoules, ${ }^{2}$ standardizing the organization of medications in the anesthesia cart is only one of the recommendations frequently cited. ${ }^{1-7}$ While no strategy will eliminate all errors completely, standardizing the medication drawer is expected to reduce selection errors and minimize the potential cognitive load from confusion and inefficient searching by healthcare professionals who work with randomly differing anesthesia cart configurations.

It is yet unknown whether these benefits can be demonstrated. One limitation of this study is the lack of data quantifying specific benefits from standardization of the anesthesia medication drawers. Merali et al. indicated that the "efficacy of the recommendations" they had formulated had "not yet been proven by formal research". They commented on the fact that "many medication safety practices involve common sense" and are "well supported by human factors in other industries". ${ }^{7}$

However, the intent of this quality assurance project was to make changes to the structure of the system rather than to study any resultant changes in process or outcome. We believe that our findings provide useful guidance and are clinically appropriate. Our methods extend previous

\footnotetext{
A CAN/CSA-Z327-M91. Standard for user-applied drug labels in anaesthesia and critical care. Canadian Standards Association 1991: $1-10$.
}

research, offer the addition of being based on Human Factors principles/guidelines, and incorporate feedback from anesthesiologists in support of an 'accepted' drug drawer solution.

Many of our results are consistent with those reported by Merry et al., including the arrangement of medications by frequency and order of use, with the left to right arrangement supporting the mental model of anesthesia used by anesthesiologists during the typical course of an operation. Similarly, we separated potentially dangerous medications, ${ }^{6,11,12}$ and rather than using a second drawer, we chose to position these medications in the back of the drawer, visually identified, and separated by an empty row. However, we chose not to use colour-coding for the base of the drawers as suggested by Merry et al. Instead, to make the colours of the vials and ampoules more prominent, we used a white liner in the drawer for visual contrast, facilitating medication detection and identification.

\section{Application of results}

\section{In the operating rooms $(O R)$}

After evaluating the results of the standardized medication drawer, we decided to implement them in all of the ORs in the three Calgary acute-care hospitals. For the same reason that a white liner was placed in the bottom of the drawer, we chose to purchase more than 100 new drawer inserts (dividers with underlay) of white plastic. Since some of the previous inserts were wooden and prone to splintering, these had the additional benefits of being easier to clean and less hazardous to users. In addition, it was possible to see through other dividers because they were transparent, and as a result, they had the associated potential problems of reduced visibility and contrast.

After inspection of a prototype, we commissioned the manufacture of the inserts, which were to be taped, labelled, and filled according to the final mock drawer. However, various difficulties were encountered during application of the labels and the clear plastic protective tape needed to cover the labels (to minimize damage from spilled medications and to facilitate cleaning).

Consequently, modifications were made to the medication drawer specifications again before more than 100 


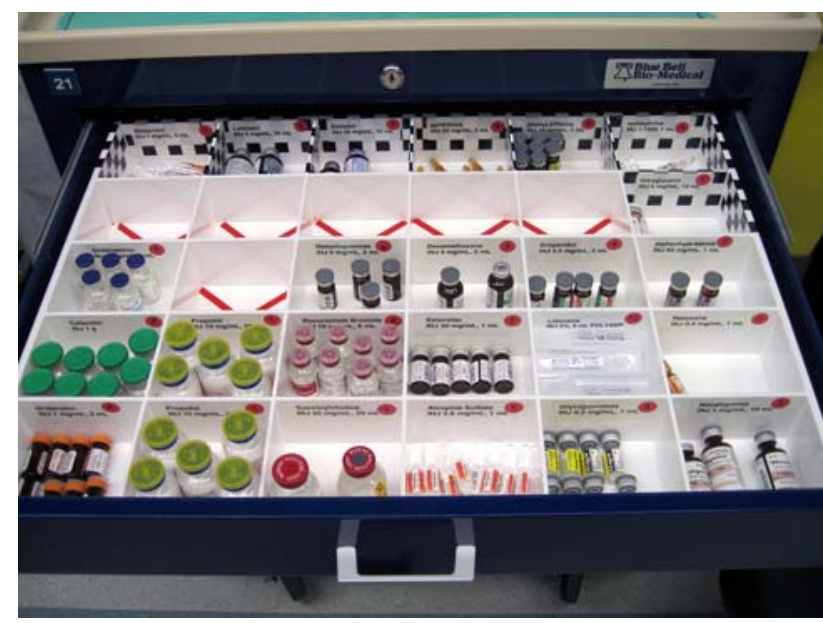

Fig. 5 Final version of the standardized medication drawer in use

drawer inserts were readied for deployment (Figure 5). A decision was made not to include labels on the base of each compartment, except for the red " $\mathrm{X}$ " in the empty compartments. The round quantity labels were originally colour-coded to differentiate single-use (red dot) from multi-dose (yellow dot) vials. (Multi-dose vials are used in Calgary only when single-use vials of medications are not commercially available, e.g., esmolol, labetalol, and neostigmine.) After a discussion with Central Pharmacy, a decision was made to use only red-coloured dots for quantity labels, because this is the colour used by Central Pharmacy to differentiate intravenously-administered medications from orally-administered medications (yellow) and topically-applied medications (green).

In addition, other changes have since been made, including modification to the standardized list of medications. For example, due to a request from one hospital, lidocaine $1 \%$ was changed to lidocaine $2 \%$. As a general rule, we recognize that ongoing proactive review of the contents of the anesthesia medication drawer is an important part of an active quality and safety program for any department.

We are now considering application of the methodology to the obstetric ORs and the cardiac ORs. Currently, two of the three hospitals now use the standardized drawer for obstetric cases, with additional obstetric medications, e.g., syntocinon, stored either on the top surface of the medication cart (Hospital \#1) or in a separate medication tote (Hospital \#3). Due to the large number of different medications in the cardiac ORs, there is not enough space in the current drawer. One solution is to purchase a five-drawer cart, with the top drawer conforming to the new standardized format and the second drawer containing the additional cardiac medications. However, we think that this choice would require further study rather than simple application of the principles / guidelines.

\section{Elsewhere}

Employing these methods for emergency crash carts is one obvious and logical application, where searching for the 'correct' medication has similar time constraints as the practice of anesthesiology. Additionally, the medication drawer redesign project has the potential to offer guidance to what is now a single health region province, not only for safety and efficiency but also for short-term economy and long-term sustainability. The standardized medication drawer has already been implemented in one private surgical clinic in Calgary as well as in a rural hospital.

Lessons learned

We did learn important lessons about the process we undertook. First, we used several different techniques during the project to encourage participation of the regional anesthesiology staff. These techniques included ensuring active engagement from the regional and site (hospital) anesthesia leaders, holding numerous presentations for all user groups at the three sites, and emphasizing the rigour of the methodology and the Human Factors rationale that went into the decision-making processes.

Second, we balanced department-driven choices against regional ones. For example, we planned to use colourcoding to differentiate single-use $v s$ multiple-use vials, postulating that the colour-coded label would be an extra visual cue to assist with the task of restocking. This department-specific colour coding was then discarded in favour of the regional use of specific colours for quantity labels.

Third, this project took 30 months from initial base-line data collection to the approval of the standardized template to installation of the final standardized drawers. When this project first started, Calgary was part of one of nine provincial health regions. Internal and external reorganization of the region contributed to the time taken to complete the project. While it might have been possible to accomplish what we did in less time, the more than two years' duration also allowed gradual acceptance of change - the important fourth stage of mandated change. ${ }^{18}$

\section{Conclusions}

This study incorporated feedback and insights from relevant users and produced generalizable and easily applied principles that can be used to determine how a list of medications should be standardized and how those medications should be positioned within a medication drawer. These principles include grouping medications by function, positioning groups according to frequency of use and in a 
left-to-right chronological order of use, isolating and visually differentiating more hazardous medications, and separating those medications that potentially could be confused with others similar in appearance. As in real estate, the guideline for anesthesia medication carts should be "location, location, location". Consideration should be given to using similar methodology in future research and quality assurance and improvement projects in order to standardize medications and their arrangement in other healthcare areas as well as to attempt to quantify the benefits of standardized medication drawers.

Acknowledgements The authors sincerely thank the members of the Anesthesia Department Quality Council for helping to recruit participants, all department members who participated in the project, and Corrine Chappell.

Funding sources None.

Conflicts of interest None declared.

\section{References}

1. Orser BA, Chen RJ, Yee DA. Drug errors in anesthetic practice: a survey of 687 practitioners. Can J Anesth 2001; 48: 139-46.

2. Currie M, Mackay P, Morgan $C$, et al. The Australian Incident Monitoring Study. The "wrong drug" problem in anaesthesia: an analysis of 2000 incident reports. Anaesth Intensive Care 1993; 21: 596-601.

3. Institute for Safe Medication Practices. ISMP quarterly action agenda - January-March 2005. 2005; Apr 7 issue. Available from URL: http://www.ismp.org/Newsletters/acutecare/articles/A2Q05 Action.asp?ptr=y (accessed October 2009).

4. Fasting S, Gisvold SE. Adverse drug errors in anesthesia, and the impact of coloured syringe labels. Can J Anesth 2000; 47: 1060-7.
5. Woods I. Making errors: admitting them and learning from them. Anaesthesia 2005; 60: 215-7.

6. Merry AF, Webster CS, Weller J, Henderson S, Robinson B. Evaluation in an anaesthetic simulator of a prototype of a new drug administration system designed to reduce error. Anaesthesia 2002; 57: 256-63.

7. Merali R, Orser BA, Leeksma A, Lingard S, Belo S, Hyland S. Medication safety in the operating room: teaming up to improve patient safety. Healthc Q 2008; 11(3 Spec No): 54-7.

8. Nielson J. Usability Engineering. San Diego: Academic Press; 1993.

9. Rozich JD, Howard RJ, Justeson JM, Macken PD, Lindsay ME, Resar RK. Standardization as a mechanism to improve safety in health care. Jt Comm J Qual Saf 2004; 30: 5-14.

10. Camire E, Moyen E, Stelfox HT. Medication errors in critical care: risk factors, prevention and disclosure. CMAJ 2009; 180: 936-43.

11. Jensen LS, Merry AF, Webster CS, Weller J, Larsson L. Evidence-based strategies for preventing drug administration errors during anaesthesia. Anaesthesia 2004; 59: 493-504.

12. Merry AF, Webster CS, Mathew DJ. A new, safety-oriented, integrated drug administration and automated anesthesia record system. Anesth Analg 2001; 93: 385-90.

13. ARECCI Alberta Research Ethics Community Consensus Initiative. Ethics Screening Tool developed by the Alberta Research Ethics Community Consensus Initiative (ARECCI) Network (2005, revised 2008). Available from URL: http://www.ahfmr. ab.ca/arecci/screening/ (accessed December 2009).

14. Wickens $C D$, Lee JD, Lui Y, Gorden-Becker SE. An Introduction to Human Factors Engineering. 2nd ed. Upper Saddle River, NJ: Pearson Education; 2004.

15. Ericsson KA, Simon HA. Protocol Analysis: Verbal Reports as Data (revised edition). Cambridge, MA: The MIT Press; 1993.

16. Shultz J, Harvie M, McDonald D, Manley J, Cole M. Standardizing the storage and labelling of medications: Part 2. Can J Hosp Pharm 2007; 60: 201-4.

17. Wheeler SJ, Wheeler DW. Medication errors in anaesthesia and critical care. Anaesthesia 2005; 60: 257-73.

18. Newcombe JP, Conrad CF. A theory of mandated academic change. Journal of Higher Education 1981; 52: 555-77. 